Check for updates

London, UK

Cite this as: $B M J 2021 ; 374: n 2218$ http://dx.doi.org/10.1136/bmj.n2218 Published: 20 September 2021

\section{Blending patient care and academia: the consultant ophthalmologist}

\author{
The ophthalmologist talks to Kathy Oxtoby about her dual role as a clinician and an academic, and \\ how her parents influenced her career
}

Kathy Oxtoby

Jugnoo Rahi is a professor of ophthalmic epidemiology at the UCL Great Ormond Street Institute of Child Health and the UCL Institute of Ophthalmology, and a consultant paediatric ophthalmologist at Great Ormond Street Hospital.

She says she was drawn to ophthalmology because of the links between vision and learning and development. "Fortunately, blindness in babies and children is rare, but its impact is incredibly profound. So, it was clear to me that working to improve the chances of someone having good eyesight as early as possible would be an extremely rewarding area of ophthalmology."

Rahi feels lucky to have the two tracks of clinical medicine and academia running alongside one another in her career. "As I was coming to the end of my clinical training as an ophthalmologist I started thinking about what I could do to help a whole population of people with eye diseases, as well as those individual patients in front of me."

Taking a masters in epidemiology at the London School of Hygiene and Tropical Medicine was a turning point for her, and it gave her the opportunity to learn about public health approaches in different countries and study with doctors from all over the world.

Rahi's interest in medicine and global health began in childhood. She was just five when she and her parents moved from north India to England in 1968. "My parents were both on separate British Council scholarships and came to England to undertake some postgraduate training," she says. "My whole life changed as a result of their decision."

Both her parents were doctors. "The possibility of working in medicine was always something that was at the back of my mind," she says. "I was brought up to think that girls can have the same careers as boys-and I was going to do whatever I wanted to do."

Rahi says that she has been supported by some incredible clinicians and scientists throughout her career, but that it was her parents "who made it clear to me what you can achieve if you aim high, work very hard, and always try to do the right thing-whether that's taking decisions on behalf of your team or calling out bad behaviour."

Having spent a large part of her early career as "the only brown young woman in the room," Rahi has occasionally had to call people out for overt discrimination. "Even now there are people in professional circles who will let slip comments like, 'You don't sound Indian'.”
"I challenge these comments," she says. "I'm conscious that I'm from a very privileged background and with that comes responsibility. I've always been someone who thinks that, if I don't say something now, someone won't think about what they've said and will do it again."

She says that her overarching aim professionally is to bring attention to childhood visual disability through advocacy work. "I want to influence the policy agenda, and to champion the need for joined up health and social care in this area," she says.

For the present, she continues to enjoy the rewarding combination of being a clinical academic. "To any young women doctors out there-know that the norms are changing and it is possible to do what I do and still have the balance you might want. It's not easy, but it is achievable. And the more women we have in academic medicine the more we can change the norms."

\section{Nominated by Mariya Moosajee}

"Jugnoo is an honest, strong, intelligent, wise, and caring leading clinician scientist in the field of paediatric ophthalmology. She is an amazing role model for early career clinical academics, and we need to improve her visibility to encourage more juniors to follow in her footsteps."

Mariya Moosajee is a professor of molecular ophthalmology at University College London

\section{Nominated by Ameenat Lola Solebo}

"Although Jugnoo has been my role model for scientific and clinical skills, l've valued her as a role model for more generic behaviours: professionalism, courtesy, and rigorous thinking. She has a sure moral compass.

"She's taught me that resilience is not putting up with bad behaviour, but rather that recovering from difficult situations is about building a coherent sense of self, and what you are prepared, and not prepared to tolerate." Ameenat Lola Solebo is a consultant ophthalmologist at Great Ormond Street Hospital NHS Foundation Trust

Jugnoo Rahi is one of 15 women featured by the BMA in its work on female role models in academic medicine. Find out more about that work here: www.bma.org.uk/what-we-do/committees/medical-academic-staff-committee/role-models-of-women-in-academic-medicine. 